\title{
Conversion in English
}

\author{
Zahraa Adnan Fadhil Al-Murib \\ Dept. of English, College of Education, Islamic University, Najaf, Iraq \\ E-mail: zahraaa.fadhil@yahoo.com
}

Received: February 13, 2021

doi:10.5296/elr.v7i1.18624
Accepted: April 13, $2021 \quad$ Published: May 9, 2021

URL: https://doi.org/10.5296/elr.v7i1.18624

\begin{abstract}
This subject review is an attempt to explore the notion of conversion in the English language. Conversion is commonly viewed as the use of the same root for different grammatical classes. Then, the study seeks to find out whether conversion is applicable to morphology only, to syntax only, or to both morphology and syntax. It carries out a theoretical account of the notion arriving at certain conclusions.
\end{abstract}

Keywords: Conversion, Morphology, Syntax, Meaning, Complete conversion, Partial conversion

\section{Introduction}

The English language is a prodigious borrower of words from other languages, though it is not the case nowadays. Like other languages, the English language has its own resources to expand its vocabulary, namely the morphological processes which conversion is one of them. Crystal in his The Story of English in 100 Words (2011) states that an easy way to have new vocabulary is to change a word into another by using it in a different way in a sentence. Some parts of speech can have their grammar shifted in this way. This process is called conversion. He (Ibid.: 14) points out that English- speakers have been doing this with words since the Anglo-Saxon times with new uses continue to emerge. He also describes Shakespeare to be the "conversion expert." He creatively converted words: "I eared her language." "He words me." He is known by his really daring conversions as he converted names of persons to verbs, like: "Petruchio is Kated." However, Shakespeare was tapping into a natural everyday usage that is still with the users of language (Ibid.: 15).

Conversion has been presented in English since the grammars of the mid $18^{\text {th }}$ century. It has been discussed as an issue in its own right as well as its being depending highly on the concept of word class. To decide whether the latter should be studied within morphology or syntax depends on the understanding of these two disciplines and how the notion of conversion is defined. In what follows, a survey of morphology and syntax is presented. The notion of conversion and how it is defined is introduced as well. Then, the study has dealt 
with the characteristics of conversion syntactically, morphologically and semantically. At the same time, a discussion of certain categories of conversion is presented to make clear to which linguistic area the notion belongs, i.e. morphology or syntax (Balteiro, 2007a).

\section{Morphology}

Morphology is defined as the branch of grammar which studies the internal structure or form of words by means of the use of a short segment of language (the morpheme). It is distinguished from syntax which deals with the sentence structure. Aronoff (1976), one of the most eminent representatives of the word- formation hypothesis, "treats words as signs: that is not just as forms, but as meaningful forms.". Accordingly, morphology "is concerned with words which are not simple signs, but which are made of more elementary ones." (Ibid.).

Therefore, if conversion is mainly concerned with simple forms, it has no place in morphology. However, if it is to be considered that not all the cases of conversion are simple units, some conversion elements can be the concern of morphology while others may not (Balteiro, 2007a).

As just seen, the inclusion of conversion in morphology is controversial and depends on how the latter is viewed.

\section{Syntax}

Syntax is the field that deals with the rules governing the way words are put together to form sentences in a language. Viewed in this way, syntax is opposed to morphology, the study of word structure (Crystal, 2008).

Many linguists believe that word- classes appearing in the same context can only be distinguished by their syntax. In other words, the way in which a word behaves towards other words in connected speech decides the word class since nouns, verbs, adjectives, and adverbs are identified by the way they behave in sentences (Balteiro, 2007a). Therefore, conversion is placed in the realm of syntax as it refers to the syntactic transposition of a word. For example, a word like wealthycan function as a noun, but it is still an adjective as it can be put in the comparative form wealthier (Aschenbrenner, 2014).

\section{Conversion: Definition}

Although the term conversion has gained a lot of attention, it is still problematic. Conversion is a term introduced by Henry Sweet in the first volume of his A New English Grammar published in 1891. It is also called zero-derivation, transposition, functional shift, or functional change.

Then, it is to be mentioned that conversion is the most popular and most defended view nowadays. However, numerous followers may be found from the $19^{\text {th }}$ century up to the present day; among whom are Sweet (1898) and Kennedy (1935). Those two figures are considered to be its most pivotal supporters. Sweet seems to have been the first to use the term conversion. He defines it as the phenomenon that change a word into another part of speech without any modification or addition, except the necessary change of inflection, etc. For him, the most important feature of conversion is the change of lexical category or part of speech. Thus, he speaks of conversion only in terms of the formal characteristics of the new part of speech that are adopted by the prototypical word, for example, inflection as in (Balteiro, 2007a): 


\section{Macrothink

1) He took a walk or three different walks of life.

After its coinage, the term conversion has been used to refer to a wide range of phenomena, all sharing one property which is the use of one form in a different syntactic context (different from its prototypical one), involving a category change besides other associated characteristics such as meaning alteration (Ibid.).

Kennedy, on the other hand, extends the use of conversion beyond referring to categorical change and regards it as a functional change not only in parts of speech but also within each part of speech. In addition, he claims that there is no change in the form of a word but only in its general functions. Similarly, Duszak points out that the change in the syntactic function is accomplished by assigning the base to a different word- class without any change in its form taking place (Ibid.: 21).

Leech conceives the phenomenon quite similarly but he mentions that conversion usually implies a change of meaning (Balteiro, 2007b).

There is a classical reference that places conversion at the crossroads of syntax, morphology, and lexical semantics. Conversion is a term used to refer to the syntactic transposition of a word, i. e. in the sense of functional change. The syntactic transposition of a word is purely grammatical matter, which has nothing to do with word- formation and derivation. Consequently, conversion reflects a stronger syntactic orientation in the understanding of the phenomenon. That is why its scope is delimited (Bauer \& Valera, 2005).

Conversion is also a linguistic process that allocates an already existing word to a new word class or syntactic category. For example, the word elec, in the sentence below, is transformed from the transitive to the intransitive category (Quirk et al., 1985: 722):

2) We elected her. (SVO)

We elected her our delegate. (SVOC)

Finally, Quirk and Greenbaum (1987), view conversion as a word formation referring to the creation of a word from an existing word without any change in form. Thus, when the noun sign shifts to the verb sign without any change in the word form we can say this is a case of conversion. However, it does not mean that this process happen to all the cases of homophones; sometimes, the connection has to do with coincidences or old etymological ties that have been lost. To illustrate, mind and manner, in the examples below, are cases of this grammatical sameness without connection by conversion, i. e. these two verbs have nothing to do with their respective noun forms in terms of semantics (Marchand, 1972):

3) I would not mind sticking around while you go shopping. (verb)

His mind is empty of thought. (noun)

4) It does not seem to matter how much he troubled her. (verb)

For that matter, I stopped contacting her. (noun)

\section{Conversion Characteristics}

While some linguists highlight one aspect, others select a different one. However, it is essential to establish the requirements of this phenomenon. Accordingly, conversion is understood as follows (Ibid.): 
- Syntactically, conversion implies extension of the functional potential of a particular lexical unit beyond the limits of its word- class, which also involves change of category or word- class.

- Morphologically, no formal alteration of the prototypical lexical unit takes place.

- Semantically, the base and the derived elements must be substantially different.

(Balteiro, 2007a)

\section{Conversion and Meaning}

Many linguists discern that meaning is important to the nature of conversion. Shanskiy recognizes a morphological and syntactic way of conversion which is a kind of lexico-semantic way. It is "when new words are formed as a result of changes in semantic aspect of this or that word by splitting of a word into homonyms." (Malyuga, 2020)

Stepanova emphasised that conversion is a phenomenon of mutual transition consisting of two elements: lexical and grammatical. In other words, a new lexical unit is formed with a new meaning that is connected with the meaning of the original word from which this new lexical word is created (Ibid.). However, converted words may or may not assume new inflections; and if the converted words take on a new inflection, conversion will be said to be full, total or complete, for example (Brown, n.p.: 2005):

5) Athens had built and manned 200 ships.

With total conversion there is extension of the functional potential of the given lexical unit, accompanied by semantic alteration and acquisition of the morphological marks typical of the new word class to which the word is converted (Balteiro, 2007b: 47).

And it is partial when the word adopts only some of the characteristics of the new word class, as in (Brown, n.p.: 2005):

6) Our six-year-old is at school.

where the adjective is said to be partially converted to noun as it functions like a noun and occupies a position that nouns usually fill. Nevertheless, lack of nominal inflections marking change of status (*six-year-olds) and the impossibility of co-occurrence with the indefinite article and other nominal modifiers (*a six-year-old) as well as modification by adverbs and gradation indicates its continuity to behave like an adjective. This point is not exempt of controversy because adjectives of nationality, for example, are used with the definite article, e.g. the English, the Spanish ... etc.; therefore they are considered to be adjectives converted into nouns denoting special groups of people (Balteiro, 2007b).

\section{Conversion Categories}

There is a number of conversion categories that are listed below:

\subsection{The Conversion of Locational Adverbs}

Locational adverbs, such as out, are converted from adverbial to predicative function as in the following examples (Haspelmath, 731):

7) We slept out. (adverbial)

The cat is out. (predicative)

It is clear that there is a change of the syntactic function, yet there is no change of the semantic category. Thus, in the derivation of icily from icy, syntactic function is changed 


\section{Macrothink

from attributive to adverbial, but the semantic category that is of property is retained. The same thing is true with the predicative conversion of out where the syntactic function is changed, whereas the semantic category that is of place is retained (Ibid.).

\subsection{The Conversion of Transitive Verbs}

There are certain transitive verbs, when transferred to the category of intransitive verbs, they are regarded as a case of conversion. These verbs are eat, elect and teach. In such a case, the clause type is going to be SV/ SVO rather than SVO/ SVOC, as in (Quirk et al., 1985):

8) They are eating. (SV)

We elected her our delegate. (SVO)

9) We elected him. (SVO)

We elected him our representative. (SVOC)

10) She is teaching. (SV)

She is teaching Chemistry. (SVO)

(Ibid.)

As the object or the complement is optionally omitted, there will also be, to a certain extent, a shift in meaning. In addition, this conversion can be applied to some transitive verbs such as hunt, along with those mentioned above, but not to others (Ibid.):

11) They are hunting deer. They are hunting.

10. They are chasing cats. * They are chasing.

Similarly is the case with ditransitive verbs where the indirect object is omitted (Ibid):

11. She gives expensive presents. $\left(\mathrm{SVO}_{d}\right) \sim$

She gives her friends expensive presents. (SVOO $d$ )

(Ibid)

However, here the conversion is not so strong, and the indirect object may be regarded with many verbs as an element similar in status to an optional element similar in status to an optional adverbial (Ibid.).

One more thing that deserves to be mentioned is that in the transitive verb there is an agent that performs some action on an object, or in some way affects it. When this verb becomes passive the agent and object change places in the sentence. Thus, John loves peter is transitive, but Peter is loved by John is passive. With the intransitive verb the matter is different and there is a fault which is that the intransitive verb is converted into a passive one. In the intransitive verb the action is limited to the agent. In other words, I perish is intransitive; I am perished is the passive form, but the latter neither expresses nor implies an agent by which I perish (Webster, 1941: 104).

\subsection{The Conversion of Adjectives}

One of the most common types of conversion, especially partial conversion is that from the adjective to the noun. There is a transformation of the structure (Art/Det+Adj+N) to (Art/Det+Adj), for example criminal in (Balteiro, 2007b):

12) It was a very/ rather criminal attack.

13) The attack seemed criminal to us. 


\section{Macrothink

is an adjective because it is used attributively and predicatively, respectively. However it is also a count noun, as it can take determiners, be inflected for number and the genitive case, and be premodified by an adjective, as in (Roy, 2019: 144):

14) The violent criminals' pleaded guilty.

Therefore, it is said that criminal is a homomorph, i.e. both an adjective and a noun where the relationship between criminal, the adjective, and criminal, the noun, is that of conversion. Below are other examples of converted adjectives to nouns (Ibid.: 145):

15) She is investigating the ancients' conception of the universe.

16) You won't find many classics in our library.

17) She considers herself an intellectual.

18) The king greeted his nobles.

19) He's a natural for the job.

Adjectives like medical, physical, and oral are also converted to nouns (Ibid.):

20) Have you had your medical/ physical yet?

21) When is your French oral?

They are different from the previous group in that a noun like examination felt to be implied which is not the case with an intellectual. On the other hand, oral has a plural form orals, that indicates complete conversion. However, medical and physical do not have plurals, hence they indicates partial conversion (Ibid.).

\subsection{The Conversion of Nouns}

Nouns may also be used in an attributive or pronominal position, modifying other nouns (Balteiro, 2007b):

22) You are a boy king.

Most often this $(\mathrm{N}+\mathrm{N})$ construction is interpreted as a partial conversion from noun to adjective. Although the word boy neither inflects for degree nor admits adverbial modification, it is considered as an adjective in the light of its attributive use (Ibid.).

The basically nominal character of a premodifying noun, such as garden in (Roy, 2019):

23) Where are you going with all the garden tools?

is shown by its correspondence to a prepositional phrase with the noun as complement: tools for the garden (Ibid.)

Other examples include (Ibid.):

24) You can't expect the city council to do nothing $\sim$ the council for the city

25) She hits a stone wall $\sim$ a wall (made) of stone

Attributive adjectives do not admit such a correspondence: the urban council, a long poem, and a thick wall. Additionally, some noun forms can function predicatively denoting style or material from which things made (Ibid.:146):

26) The floor is concrete.

27) This porcelain is Worcester.

28) Those pies are apple. (informal) 


\section{Macrothink}

\section{Conclusions}

Out of what has been accounted for, it is concluded that conversion is a process which is applicable to both morphology and syntax. In terms of morphology it is a word- formation process and in terms of syntax it is a case where elements changes their functions according to the clause type. Meaning is also important to conversion since new lexical units are formed with a new meaning that is related to the original word from which these new words are converted. Furthermore, it is concluded that conversion has certain characteristics along with certain categories that include the conversion of locational adverbs, transitive verbs, and adjectives. The adverb changes its syntactic function from adverbial to predicative but not its semantic category. The transitive verb convert its function to be intransitive. This conversion is limited to certain transitive verbs like, eat, elect, teach, etc. but not to others like, chase. Besides, the transitive verb can be used in the passive form where the $\mathrm{S}$ and $\mathrm{O}$ change functions. However, the transitive verb cannot because there is no object and only agent. Thus, there is no change of roles. As for adjectives, they are transformed from the structure $($ Art/Det + Adj $+\mathrm{N})$ to $($ Art/Det + Adj). They are considered to be homomorphs indicating both full and partial conversion. Like adjectives, nouns can also converted to adjectives that can function attributively and predicatively.

\section{References}

Aschenbrenner, A. (2014). Adjectives as Nouns Mainly as Attested in Boethius Translations from Old to Modern English and in Modern German. Munchin: Herbert Utz Verlag.

Balteiro, I. (2007a). A Contribution to the Study of Conversion. New York: Waxmann.

Balteiro, I. (2007b). The Dictionary of Conversion in English. Berlin: Peter Lang.

Bauer, L., \& Valera, S. (2005). Approaches to Conversion/Zero- Derivation. New York: Waxmann.

Crystal, D. (2011). The Story of English in 100 Words. London: Profile Books LTD.

Haspelmath, M. (2001). Language Typology and Language Universals. New York: de Grayter. https://doi.org/10.1515/9783110171549.2

Malyuga, E. N. (ed.). (2020). Functional Approach to Professional Discourse Exploration in Linguistics. Beach Road: Springer. https://doi.org/10.1007/978-981-32-9103-4

Marchand, H. (1972). Studies in Syntax and Word-Formation. München: Wilhem Fink.

Quirk, R., \& Greenbaum, S. (1987). A University Grammar of Englis., London: Longman.

Quirk, R., Greenbaum, S., Leech, G., \& Svartvik, J. (1985). A Comprehensive Grammar of the English Language. London: Longman.

Roy, R. (2019). Ranjesh's Practical Global English Grammar, Composition and Usages. Delhi: BlueRose.

Sweet, H. (1891). A new English Grammar: Logical and Historical. Oxford: Clarendon Press. 


\section{Macrothink

\section{Copyright Disclaimer}

Copyright reserved by the author(s).

This article is an open-access article distributed under the terms and conditions of the Creative Commons Attribution license (http://creativecommons.org/licenses/by/4.0/). 